\section{Loyalitas Kreativitas \\ Aldi Masyarakat Kreatif}

P-ISSN 2722-2101, E-ISSN 2722-4201

Program Studi Ekonomi Manajemen Universitas Pamulang

Jurnal LOKABMAS Kreatif Vol.01, No.02 Hal.82-

87Email:jurnalkreatif.manajemen@gmail.com

\title{
PENERAPAN MANAJEMEN BERBASIS AKTIVITAS DALAM USAHA KECIL DAN MENENGAH DI KELURAHAN PANINGGILAN UTARA KECAMATAN CILEDUG KOTA TANGERANG
}

\author{
Abdul Rahman safiih, Achmad Ludvy, Agus Suhartono, Indra Januar Rukmana, Aan Purnama \\ Dosen Manajemen Universitas Pamulang \\ Email dosen02457@unpam.ac.id
}

\begin{abstract}
ABSTRAK
Tujuan dari pelaksanaan Pengabdian Kepada Masyarakat yang berjudul "Penerapan Manajemen Berbasis Aktivitas Dalam Usaha Kecil Dan Menengah Di Kelurahan Paninggilan Utara, Kecamatan Ciledug, Kota Tangerang" adalah sebagai upaya pemenuhan kewajiban Tri Dharma Perguruan Tinggi. Pengabdian Kepada Masyarakat dilakukan di Karang Taruna lingkungan RW 013 Kelurahan Paninggilan, Kecamatan Ciledug, Kota Tangerang

Berdasarkan hal di atas, kegiatan pengabdian kepada masyarakat dapat membantu memahami manajemen dalam usaha kecil dan menengah, Memberikan implementasi yang baik dalam menentukan skala prioritas usaha apa yang akan dijalankan dan memberikan wawasan kepada masyarakat

Metode yang digunakan adalah metode survey, penyuluhan dan penyampaian materi secara langsung serta simulasi dan diskusi mengenai pengelolaan dan manajemen dalam usaha kecil dan menengah

Hasil Pengabdian Kepada Masyarakat ini adalah bahwa akan dilakukan pendampingan dalam manajemen dalam usaha kecil dan menengah pada warga Kelurahan Paninggilan Utara, Kecamatan Ciledug, Kota Tangerang.
\end{abstract}

Kata Kunci : Penyuluhan, Pengelolaan, Manajemen dalam usaha kecil dan menengah

\begin{abstract}
The purpose of the implementation of Community Service entitled "Application of ActivityBased Management in Small and Medium Enterprises in Paninggilan Utara Village, Ciledug District, Tangerang City" is an effort to fulfill the Tri Dharma College's obligations. Community Service is carried out in Karang Taruna, neighborhood RW 013, Paninggilan Village, Ciledug District, Tangerang City Based on the above, community service activities can help understand management in small and mediumsized businesses, provide good implementation in determining the priority scale of what business will be run and provide insight to the community

The method used is a survey method, counseling and delivery of material directly as well as simulations and discussions on management and management in small and medium businesses

The Result of Community Service is that assistance will be provided in management in small and mediumsized businesses to residents of the North Paninggilan Village, Ciledug District, Tangerang City.
\end{abstract}

Keywords: Counseling, Management, Management in small and medium businesses

\section{PENDAHULUAN}

Kebijakan pemberdayaan UKM dalam secara umum diarahkan untuk mendukung upaya-upaya penanggulangan kemiskinan dan kesenjangan, penciptaan kesempatan kerja danpeningkatan ekspor, serta revitalisasi pertanian dan perdesaan, yang menjadi prioritas pembangunan nasional dalam tahun 2006. Dalam kerangka itu, pengembangan usaha kecil dan menengah (UKM) diarahkan 


\section{Loyalitas Kreativitas \\ Aldi Masyarakat Kreatif}

P-ISSN 2722-2101, E-ISSN 2722-4201

Program Studi Ekonomi Manajemen Universitas Pamulang Jurnal LOKABMAS Kreatif Vol.01, No.02 Hal.8287Email:jurnalkreatif.manajemen@gmail.com agar memberikan kontribusi yang signifikan terhadap penciptaan kesempatan kerja, peningkatan ekspor dan peningkatan daya saing, sementara itu pengembangan usaha skala mikro diarahkan untuk memberikan kontribusi dalam peningkatan pendapatan masyarakat berpendapatan rendah, khususnya di sektor pertanian dan pedesaan. Kinerja nyata yang dihadapi oleh sebagian besar usaha terutama mikro, kecil, dan menengah (UMKM) di Indonesia yang paling menonjol adalah rendahnya tingkat produktivitas, rendahnya nilai tambah, dan rendahnya kualitas produk. Walau diakui pula bahwa UMKM menjadi lapangan kerja bagi sebagian besar pekerja di Indonesia , tetapi kontribusi dalam output nasional di katagorikan rendah. Hal ini dikarenakan UMKM, khususnya usaha mikro dan sektor pertanian (yang banyak menyerap tenaga kerja), mempunyai produktivitas yang sangat rendah. Bila upah dijadikan produktivitas, upah ratarata di usaha mikro dan kecil umumnya berada dibawah upah minimum. Kondisi ini merefleksikan produktivitas sektor mikro dan kecil yang rendah bila di bandingkan dengan usaha yang lebih besar.

Di antara berbagai faktor penyebabnya, rendahnya tingkat penguasaan teknologi dan kemampuan wirausaha di kalangan UMKM menjadi isu ekonomi yang mengemuka saat ini. Pengembangan UMKM secara parsial selama ini tidak banyak memberikan hasil yang maksimal terhadap peningkatan kinerja UMKM, perkembangan ekonomi secara lebih luas mengakibatkan tingkat daya saing kita tertinggal dibandingkan dengan negaranegara tetangga kita seperti misalnya Malaysia. Karena itu kebijakan bagi UMKM bukan karena ukurannya yang kecil, tapi karena produktivitasnya yang rendah. Peningkatan produktivitas pada UMKM, akan berdampak luas pada perbaikan kesejahteraan rakyat karena UMKM adalah tempat dimana banyak orang menggantungkan sumber kehidupannya. Salah satu alternatif dalam meningkatkan produktivitas UMKM adalah dengan melakukan modernisasi 2 sistem usaha dan perangkat kebijakannya yang sistemik sehingga akan memberikan dampak yang lebih luas lagi dalam meningkatkan daya saing daerah.

Kewirausahaan dan UMKM adalah "anak tiri" dari perekonomian Indonesia Karenawalaupun sektor ini menyerap banyak sekali tenaga kerja namun entah kenapa pemerintah kita (sebelumnya) kurang begitu memperhatikan dan membantu perkembangan para pelaku wirausaha dan UMKM. Berdasarkan data UMKM tahun 2012 dari Kementerian Koperasi dan UKM Republik Indonesia, sektor UMKM menyumbang sekitar 59.08\% dari GDP Indonesia - sekitar 528.7 milyar USD - dan menyerap $97.16 \%$ tenaga kerja - 107 juta tenaga kerja. Melihat angka ini, kita bisa lihat betapa pentingnya kontribusi UMKM terhadap perekonomian Indonesia. Namun sayangnya pemerintah kita tidak memiliki kebijakan komprehensif untuk membantu perkembangan wirausaha dan UMKM. Memang ada beberapa kebijakan pro UMKM, seperti Kredit Usaha Rakyat (KUR), yang sudah dimulai oleh pemerintahan era SBY. Namun dampaknya masih kurang terasa karena pada faktanya hanya sekitar $25 \%$ (13 juta) dari pelaku UMKM yang sudah bisa mendapatkan akses ke lembaga finansial (bank). Selain itu, kebijakan yang dikeluarkan oleh pemerintahan SBY hanyalah menyentuh satu aspek, yaitu pembiayaan. Padahal ada banyak aspek yang perlu distimulasi oleh pemerintah untuk mengembangkan sektor wirausaha dan UMKM lebih lanjut.

Berangkat dari latar belakang tersebut, tim Abdimas dari Program 
Loyalitas Kreativitas
Aldi Masyarakat Kreatif
P-ISSN 2722-2101, E-ISSN 2722-4201

Program Studi Ekonomi Manajemen Universitas Pamulang Jurnal LOKABMAS Kreatif Vol.01, No.02 Hal.8287Email:jurnalkreatif.manajemen@gmail.com
Manajemen Universitas Pamulang mengadakan kegiatan Pengabdian kepada Masyarakat dengan bermitra bersama warga di Kelurahan Paninggilan Utara Kecamatan Ciledug Kota Tangerang untuk dapat memberikan pengajaran bahasa bagi para siswa. Selagi tim Abdimas memberi pengarahan kepada warga di Kelurahan Paninggilan Utara Kecamatan Ciledug Kota Tangerang dapat mengadaptasi proses masukan yang dilakukan tim Abdimas, hingga kedepannya program ini dapat berkelanjutan.

\section{RUMUSAN MASALAH}

Berdasarkan analisis situasi yang telah dipaparkan. Maka terdapat dua masalah yang dirumuskan dalam kegiatan pengabdian ini, yaitu

1. Potensi apa saja yang dapat di olah dan dibentuk oleh warga di kelurahan Paninggalan Utara, Kecamatan Ciledug, kota Tangerang?

2. Bagaimana cara penerapan manajemen berbasis aktivitas pada usaha kecil dan menengah yang tepat bagi warga di kelurahan Paninggilan Utara, Kecamatan Ciledug, kota Tangerang?

\section{TUJUAN PELAKSANAAN}

Tujuan pelaksanaan pengabidian msyarakat di karang taruna paninggilan adalah:

1. Menggali potensi usaha warga di Kelurahan Paninggilan Utara, Kecamatan Ciledug, Kota Tangerang

2. Menerapkan manajemen berbasis aktivitas usaha kecil dan menengah pada warga di Kelurahan Paninggilan Utara, Kecamatan Ciledug, Kota Tangerang

3. Membiasakan warga di Kelurahan Paninggilan Utara, Kecamatan Ciledug, Kota Tangerang untuk mengaplikasikan manajemen berbasis aktivitas usaha kecil dan menengah dalam kegiatan seharihari.

\section{TINJAUAN PUSTAKA}

UMKM adalah unit usaha produktif yang berdiri sendiri, yang dilakukan oleh orang perorangan atau badan usaha disemua sektor ekonomi. Pada prinsipnya pembedaan antara usaha mikro, usaha kecil, usaha menengah, usaha besar umumnya didasarkan pada nilai aset awal (tidak termasuk tanah dan bangunan), omset rata-rata per tahun, atau jumlah pekerja tetap. Namun, definisi UMKM berdasarkan tiga alat ukur ini berbeda menurut negara. Oleh karena itu memang sulit membandingkan pentingnya atau peran UMKM antar negara.16 Di Indonesia definisi UMKM diatur dalam UndangUndang Republik Indonsia Nomor 20 Tahun 2008 tentang UMKM.

Dalam Bab 1 (Ketentuan Umum), pasal 1 dari UU tersebut, dinyatakan bahwa usaha mikro adalah usaha produktif milik orang-perorangan dan badan usaha perorangan yang memenuhi usaha mikro sebagaimana diatur dalam UU tersebut. Usaha kecil adalah usaha ekonomi produktif yang berdiri sendiri, yang dilakukan oleh orang-perorangan atau badan usaha yang bukan merupakan anak perusahaan atau bukan cabang perusahaan yang dimiliki, dikuasai, atau menjadi bagian baik langsung maupun tidak langsung dari usaha mikro atau usaha besar yang memenuhi kriteria usaha kecil sebagaimana telah diatur dalam UU tersebut. Sedangkan usaha menengah adalah usaha ekonomi produktif yang berdiri sendiri, yang dilakukan oleh orangperorangan atau badan usaha yang bukan merupakan anak perusahaan atau bukan cabang perusahaan yang dimiliki, dikuasai, atau menjadi bagian baik langsung maupun tidak langsung dari usaha mikro, usaha kecil atau usaha besar yang memenuhi kriteria usaha mikro sebagaimana dimaksud dalam UU 


\section{Loyalitas Kreativitas \\ Aldi Masyarakat Kreatif}

P-ISSN 2722-2101, E-ISSN 2722-4201

Program Studi Ekonomi Manajemen Universitas Pamulang

Jurnal LOKABMAS Kreatif Vol.01, No.02 Hal.82-

87Email:jurnalkreatif.manajemen@gmail.com tersebut. Berdasarkan Undang- Undang Nomor 20 Tahun 2008 tentang UMKM, maka definisi dari masing-masing usaha adalah sebagai berikut:18

Usaha Mikro adalah usaha dengan kekayaan bersih kurang dari 50

juta rupiah atau menghasilkan penjualan kurang dari 300 juta rupiahselama satu tahun.

1. Usaha kecil adalah usaha dengan kekayaan antara 50 sampai 500 juta rupiah atau menghasilkan penjualan antara 300 juta hingga 2,5 miliar rupiah selama satu tahun.

2. Usaha menengah adalah usaha dengan kekayaan atara 500 juta sampai 10 miliar rupiah atau menghasilkan penjualan antara 2,5 hingga 50 miliar rupiah selama satu tahun.

3. Usaha menengah adalah usaha dengan kekayaan atara 500 juta sampai 10 miliar rupiah atau menghasilkan penjualan antara 2,5 hingga 50 miliar rupiah selama satu tahun.

Diakui bahwa usaha mikro kecil dan menengah (UMKM) memainkan peran penting di dalam pembangunan dan pertumbuhan ekonomi, tidak hanya di negara-negara sedang berkembang, tetapi juga dinegara-negara maju. Di negara maju UMKM sangat penting, tidak hanya karena kelompok usahanya tersebut menyerap paling banyak tenaga kerja dibandingkan usaha besar, tetapi juga kontribusinya terhadap pembentukan dan pertumbuhan produk domestik bruto (PDB) paling besar dibandingkan kontribusinya dari usaha besar. Berdasarkan kontribusi UMKM terhadap PDB per sektor dapat diketahui bahwa kontribusi UMKM terbesar berada di sektor PPKP dengan unit UMKM sebesar 49.58\%, disusul dengan sektor PHR dengan $29.56 \%$. Industri pada sektor ini sangat potensial dikembangkan sejak dari mikro, dan ada peluang dikembangkan untuk menjadi industri besar.

\section{METODE PELAKSANAAN}

Metode pelaksanaan yang dilakukan dalam kegiatan pengabdian kepada masyarakat ini adalah meliputi kegiatan:

1. Memberikan kegiatan mengaplikasikan manajemen berbasis aktivitas usaha kecil dan menengah. metode komunikatif, yaitu dengan presentasi.

2. Penerapan langsung materi dalam bentuk praktik sederhana meliputi pemahaman manajemen berbasis aktivitas usaha kecil dan menengah.

\section{HASIL DAN PEMBAHASAN}

Pengabdian Masyarakat yang diselenggarakan pada tanggal 05 April sampai dengan 07 April 2019 yang dilakukan oleh dosen-dosen Universitas Pamulang yaitu Abdul Rahman Safiih, SE., MM, Achmad ludvy, SE., MM, Agus Suhartono, SE., MM, Indra Januar Rukmana, SE., MM, Aan Purnama, SE., MM. berjalan dengan lancar dan mendapat antusias dari Karang Taruna Lingkungan RW 013, Kelurahan Paninggilan, Kecamatan Ciledug, Kota Tangerang. Salah satu kendala yang dihadapi oleh Karang Taruna Lingkungan RW 013, Kelurahan Paninggilan, Kecamatan Ciledug, Kota Tangerang adalah tidak adanya sumber daya manusia yang mumpuni untuk mengaplikasikan manajemen berbasis aktivitas usaha kecil dan menengah kepada para Warga. Mengaplikasikan manajemen berbasis aktivitas usaha kecil dan menengah penting untuk dilakukan karena para warga memiliki potensi untuk belajar dalam berwirausaha, di samping itu para warga pun antusias untuk mempelajarinya. Sementara itu, program pengajaran ini belum menjadi program tetap yang berkelanjutan dikarenakan para warga kurang menguasai materi. Hal ini dinilai sebagai tantangan yang dihadapi 


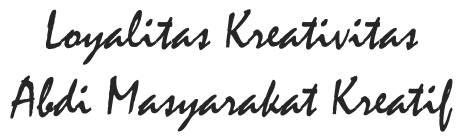

Loyalitas Kreativitas

Aldi Masyarakat Kreatif
Lingkungan RW 013, Kelurahan Paninggilan, Kecamatan Ciledug, Kota Tangerang untuk dapat memenuhi antusiasme warga untuk mempelajarai bidang wirausaha. Uraian kegiatan yang telah dilakukan dijabarkan sebagai berikut :

1. Pemberian materi awal terkait kosakata bahasa Indonesia yang akan dipelajari

Kegiatan ini dilakukan dengan harapan agar warga mampu memahami terlebih dahulu mengenai materi yang akan disampaikan. Tahapan pertama ini meliputi pengenalan jenis-jenis usaha apa saja yang bisa digeluti dalam masa pandemi ini., variasi usaha yang disampaikan agar dapat memberikan gambaran apa yang akan di berdayakan nanti.

2. Proses Pelatihan Materi Dasar Wirausaha (UKM)

Pada tahap ini dilakukan pemberian materi dasar Wirausaha atau UKM. Materi dasar ini meliputi penguasaan manajemen waktu, variasi usaha, dan bahan baku yang mudah dan terjangkau serta mudah ditemukan oleh warga dalam kesehariannya. Pelatihan materi ini dilakukan dengan metode yang komunikatif, yaitu dengan presentasi slide dan dipandu oleh tim Abdimas.

3. Evaluasi Materi

Setelah dilakukan pelatihan materi manajemen berbasis aktivitas usaha kecil dan menengah kepada para warga, selanjutnya dilakukan evaluasi mengenai materi yang telah disampaikan. Hal ini bertujuan untuk menakar keefektifan metode manajemen berbasis aktivitas usaha kecil dan menengah untuk mengimplementasikan dalam kehidupan sehari- hari. Proses evaluasi ini dilakukan dalam 2 tahap. Pertama, evaluasi awal, yaitu evaluasi yang dilakukan di hari yang sama, tepat setelah materi disampaikan. Kedua, evaluasi akhir, yaitu evaluasi yang dilakukan pada kunjungan terakhir tim
Abdimas di Lingkungan RW 013, Kelurahan Paninggilan, Kecamatan Ciledug, Kota Tangerang. Pada evaluasi ini warga diminta untuk memberanikan dalam mempraktekan materi tersebut.

\section{KESIMPULAN DAN SARAN}

\section{Kesimpulan}

Kegiatan ini mendapat respons yang baik dari Kepala Rukun Warga 013 sebagai penggagas berdirinya Karang Taruna Lingkungan RW 013 tersebut. Warga yang didominasi oleh usia antara dari 18 tahun ini sangat antusias mengikuti proses pembelajaran yang disampaikan oleh tim Abdimas Program Manajemen Universitas Pamulang.

Simpulan dari kegiatan pelatihan materi manajemen berbasis aktivitas usaha kecil dan menengah ini adalah metode komunikatif khususnya menggunakan metode presentasi slide dan praktek langsung. Hal ini terlihat dari kemampuan para warga ketika mereview kembali materi yang telah disampaikan. Di samping itu, warga pun dapat mencerap materi dengan sangat baik, pada situasi ini warga mampu mengidentifikasi penguasaan manajemen waktu, variasi usaha, dan bahan baku yang mudah dan terjangkau dalam metode manajemen berbasis aktivitas usaha kecil dan menengah ini.

\section{Saran}

Saran bagi tim selanjutnya yang akan melakukan pengabdian dan berorientasi pada pembahasan praktek kepada para anak muda, maka metode komunikatif dapat digunakan sebagai metode yang efektif untuk pengajaran materi ini. Hal ini bertujuan untuk mempermudah warga dalam menyerap materi, karena metode pengajaran baiknya disesuaikan dengan proses perkembangan hasil dari review yang sebelumnya dilakukan.

\section{DAFTAR PUSTAKA.}

Agustina, Tri Siwi. 2015. Kewirausahaan: Teori dan Penerapan 


\section{Loyalitas Kreativitas \\ Aldi Masyarakat Kreatif}

P-ISSN 2722-2101, E-ISSN 2722-4201

Program Studi Ekonomi Manajemen Universitas Pamulang Jurnal LOKABMAS Kreatif Vol.01, No.02 Hal.8287Email:jurnalkreatif.manajemen@gmail.com pada Wirausaha dan UKM di di Indonesia. Jakarta: Mitra Wacana Media.

Gitosudarmo, Indrianyo, 2000 Manajemen Pemasaran, Yogyakarta : BPFE Siagian, 2008, Manajemen Stratejik.

Hasibuan,H.Malayu S.P, 2011. Manajemen, Dasar, pengertian dan Masalah. Jakarta : Bumi Aksara Bangsawan, Satria, 2016.Manajemen Pemasaran Usaha Kecil. Yogyakarta : Graha Ilmu Damayanti, C. (2015). Packaging The Brand. Modul pelatihan. Rumah Kemasan Bandung Firzan,

M. (2015). Modul Pelatihan Branding Untuk Usaha Kecil Menengah. Modul. Rumah Kemasan Bandung

Pasaribu, V. L. D., Agrasadya, A., Shabrina, N., \& Krisnaldy, K. (2020). MENJADI ENTERPRENEUR MUDA YANG MEMILIKI JIWA LEADERSHIP UNTUK MENGHADAPI MASA DEPAN. Abdi Laksana, 1(1)

Pasaribu, V. L. D., Elburdah, R. P., Sudarso, E., \& Fauziah, G. (2020). PENGGUNAAN MANAJEMEN WAKTU TERHADAP PENINGKATAN PRESTASI BELAJAR DI SMP ARAISIYAH. Jurnal ABDIMAS, 1(1)

Pasaribu, V. L. D., Susanti, F., \& Hartuti, E. T. K. (2019). MEMOTIVASI SISWA DAN SISWI SMK LETRIS INDONESIA DI DALAM MENENTUKAN PILIHAN UNTUK MELANJUTKAN PENDIDIKAN ATAU BEKERJA SETELAH LULUS SEKOLAH. Jurnal Pengabdian Dharma Laksana, 1(2), 161-172.

Pasaribu, V. L. D., Oktrima, B., Prabowo, B., Arianto, N., \& Haryoko, U. B. (2020). PROGAM PENDAMPINGAN DAN PENYELENGGARAAN PENDIDIKAN
ANAK PADA USIA DINI TERHADAP PRESTASI BELAJAR DILINGKUNGAN RT 020 RW 009. KEL GIRI PENI. KEC WATES. YOGYAKARTA. JURNAL LOKABMAS KREATIF, 1(1), 71-75.

Pasaribu, V. L. D., Sulaiman, S., Sutiman, S., Thaharudin, T., \& Purnomo, B. Y. (2020). PENGENALAN LETAK POSYANDU TERDEKAT DIKELURAHAN PISANGAN DENGAN MANAJEMEN PEMASARAN REVOLUSI 4.0 UNTUK MENINGKATKAN PENGETAHUAN MASYARAKAT LETAK DAN FUNGSI POSYANDU TERDEKAT PADA KELURAHAN PISANGAN. DEDIKASI PKM, 1(1), 105-110.

Pasaribu, V. L. D., \& Krisnaldy, K. (2019). Manajemen Risiko dan Asuransi.

\section{DOKUMENTASI KEGIATAN}
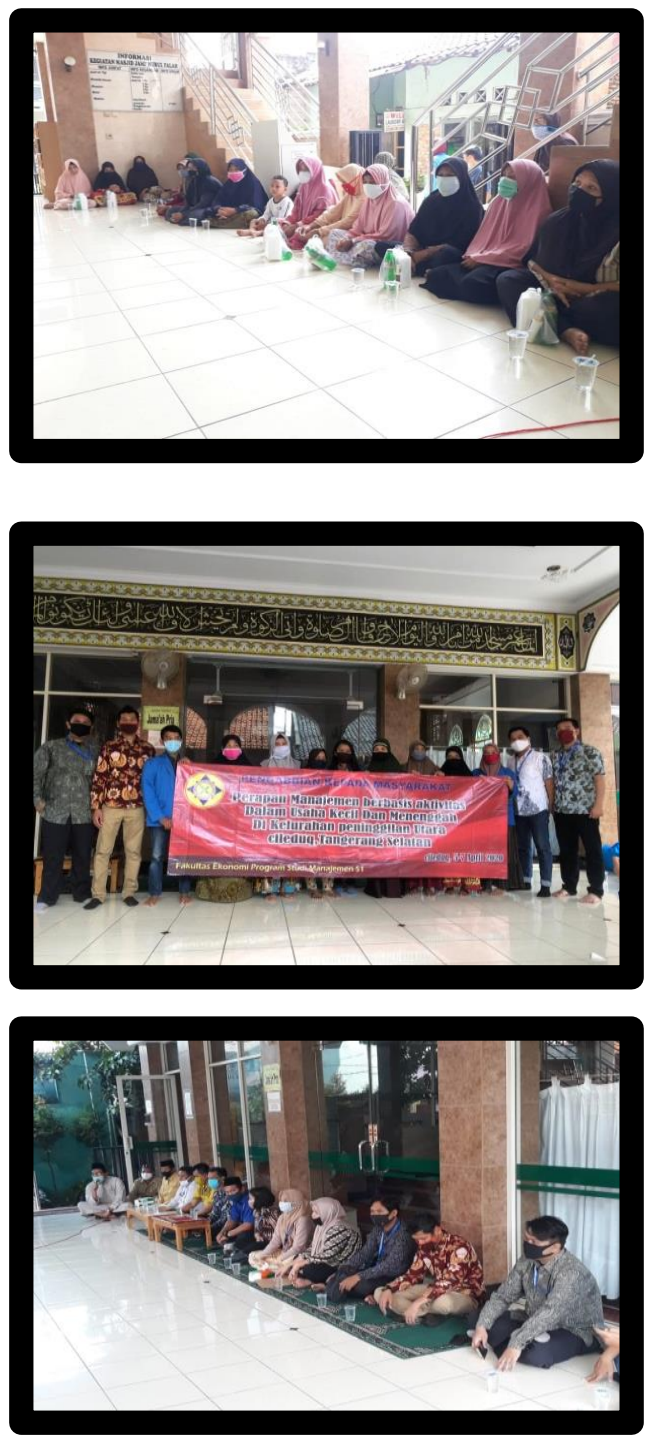